\title{
Effect of low dose oral contraceptives on exercise performance
}

\author{
Randall W Bryner, Roger C Toffle, Irma H Ullrich, Rachel A Yeater
}

\begin{abstract}
Objective-to examine the effect of cycle phase or a low dose oral conraceptive on exercise performance in young women. Methods-As controls, 15 men were tested twice by a maximal treadmill test ( $/ \mathrm{o}_{2}$ max) and by an endurance run $14 \mathrm{~d}$ apart to determine performance variability from causes other than hormonal fluctuations. Ten women ages 18-30 were then tested for $\mathrm{Vo}_{2}$ max and endurance in the same way in both the follicular and the luteal phase (random order, ovulation assessed by sonography). They were then randomly assigned to placebo $(n=3)$ or oral contraceptive (1 mg norethindrone and $35 \mu \mathrm{g}$ ethinyl oestradiol) $(n=7)$ for 21 days. Tests were repeated during the first and third weeks of treatment. $\mathrm{Vo}_{2}$ max and endurance tests were compared in the men and control cycle of the women by using independent $t$ tests on percent change. The data for both cycles in the women were analysed by repeated measures ANOVA.
\end{abstract}

Results-There was no difference in per cent change in total test time, $\mathrm{Vo}_{2} \max$, or breathing frequency between the men and women in either test. Data obtained during the $\mathrm{Vo}_{2}$ max test revealed no difference between the follicular and luteal phases of the menstrual cycle for total test time $\left[\begin{array}{llllll}11.8 & (\mathrm{SD} & 2.3) & v & 12.6 & (2.3) \\ \mathrm{min}\end{array}\right], \mathrm{Vo}_{2}$ $\left[41.6(12 \cdot 1)\right.$ v $\left.39.7(11 \cdot 4) \quad \mathrm{ml} \cdot \mathrm{kg}^{-1} \cdot \mathrm{min}^{-1}\right]$, or breathing frequency $[26.8(3.5) v 27 \cdot 3$ (9.9) breaths $\left.\cdot \mathrm{min}^{-1}\right]$ respectively, or during the first and third weeks of treatment [total test time 12.0 (2.5) $v 12.8(2.4) \mathrm{min}$; $\mathrm{Vo}_{2} 37 \cdot 3(7 \cdot 4)$ v $41 \cdot 0(12 \cdot 4) \mathrm{ml} \cdot \mathrm{kg}^{-1} \cdot \mathrm{min}^{-1}$; breathing frequency $27.8(4 \cdot 2) v 27 \cdot 7(3.4)$ breaths $\cdot \mathrm{min}^{-1}$, respectively]. Data obtained during the endurance test revealed no difference between the follicular and luteal phase of the menstrual cycle for total test time $[20.5(15.7) v 16.2(8.5) \mathrm{min}], \mathrm{Vo}_{2}$ $\left[37.5(9.4) \quad v 32.9(8 \cdot 1) \mathrm{ml} \cdot \mathrm{kg}^{-1} \cdot \mathrm{min}^{-1}\right]$, or breathing frequency $[32.0(6.0) \quad v \quad 33.2$ $(5 \cdot 1)$ breaths $\cdot \mathrm{min}^{-1}$, respectively], or during the first and third weeks of treatment [total test time $32 \cdot 3(34.9) v 30.6(30 \cdot 1) \mathrm{min}$; $\mathrm{Vo}_{2} 33.9(10 \cdot 1)$ v $35 \cdot 2(8 \cdot 6) \mathrm{ml} \cdot \mathrm{kg}^{-1} \cdot \mathrm{min}^{-1}$; breathing frequency $34.0(5 \cdot 9) v 34 \cdot 8(5 \cdot 3)$ breaths' min $^{-1}$, respectively].

Conclusions-Neither cycle phase nor a low dose oral contraceptive containing $1 \mathrm{mg}$ norethindrone adversely affects per- formance during a maximal treadmill test or endurance run.

(Br F Sports Med 1996;30:36-40)

Key terms: maximum oxygen consumption; endurance performance; menstrual cycle; low dose contraceptive.

Athletic amenorrhea is a condition which affects many young women who participate in strenuous athletic sports. Although the exact mechanisms which lead to this condition are not clearly understood, it is clear that blood levels of oestradiol and progesterone are reduced in these women. Oestrogen treatment has been advocated to prevent osteoporosis associated with exercise induced hypogonadotropic hypogonadism (athletic amenorrhoea). Unopposed oestrogens, however, are associated with an increase in adverse endometrial effects such as carcinoma and dysfunctional uterine bleeding; these may be avoided by the addition of a progestational agent. Since combination oral contraceptives contain a progestin as well as an oestrogen, such a formulation appears to be a convenient method of replacement therapy.

The observation that the physiological increase in ventilation that occurs during pregnancy is mediated by progesterone has led to the investigation of the effect of various progestational agents upon respiratory function. ${ }^{12}$ The administration of medroxyprogesterone acetate (MPA) to male subjects significantly increased both resting and exercise ventilation compared to control values. ${ }^{3}$ This enhancement of the normal ventilatory response to exercise might result in the consumption of energy by respiratory muscles that would otherwise be available for other muscular activities. As a result, exercise performance could be impaired. Increased ventilation rates similar to those experienced during maximum exercise can cause a rise in blood lactate in resting subjects, indicating significant anaerobic metabolism in the respiratory muscles. ${ }^{4}$

Conflicting data have been reported as to the effect of oral contraceptives upon maximum or submaximal performance as measured by laboratory tests. ${ }^{5-7} \mathrm{Six}$ months of oral contraceptive use during an exercise training programme of similar duration was associated with an $8 \%$ decrease in maximum oxygen uptake. ${ }^{7}$ No significant decrease was documented in maximum exercise time or maximum oxygen consumption following two weeks of MPA administration to males. ${ }^{3}$ However, five of six of these subjects did complain of increased 
exertional dyspnoea on MPA and identified dyspnoea as the symptom that limited their performance. No subject made this complaint during a placebo period. The concern therefore is that the progestin component of a combination oral contraceptive might result in energy expenditure for respiration rather than athletic performance. The effects of oral contraceptives upon exercise performance might not be detected by an acute laboratory test, but may become apparent only when evaluated by a test that simulates an athletic event. The purpose of this study was therefore to examine the effect of cycle phase or an oral contraceptive containing $1 \mathrm{mg}$ norethindrone and $35 \mu \mathrm{g}$ ethinyl oestradiol upon a maximum $\dot{\mathrm{V}}_{2}$ test and an endurance run in young women.

\section{Methods}

Fifteen male and 10 female volunteers ages 18-30 years were recruited by poster and advertisement. Male volunteers were used to assess the reliability of repeated $\mathrm{VO}_{2} \max$ endurance testing, since their results would not be influenced by a menstrual cycle. In order to qualify, female volunteers were required to have menses at 25-35 d intervals with symptoms suggestive of ovulation for at least the previous one year, to not have used oral contraceptives within the preceding six months, and to have no contraindication to the use of oral contraceptives. After review of the menstrual history, the expected day of ovulation was estimated as: average cycle length minus 12-14 d. The mid-follicular phase was determined by: estimated cycle day of ovulation divided by two. Serial transabdominal ultrasound examinations using an ATL UltraMark IV sector scanner were performed in the periovulatory time frame to confirm that ovulation did in fact occur. The mid-luteal phase was defined as being 6-8 d after the date of ovulation, as assessed by ultrasound.

Subjects came into the human performance laboratory before testing to be familiarised with the testing environment and apparatus. Informed consent was obtained and the protocol was explained completely to each subject. On the days of testing, a modified Balke treadmill protocol was used to determine maximum oxygen consumption $\left(\mathrm{V}_{2} \max \right){ }^{8}$ Following a 2 min warm up, the treadmill speed was set at $3.0-3.5 \mathrm{mph}$ dependent on stride length of the subject. The elevation of the treadmill was increased each minute by $1 \%$ until volitional fatigue occurred. During maximum and endurance testing, subjects breathed continuously into a Hans Rudolf valve with plastic tubing connected to the inlet of a pneumotach. Expired concentrations of oxygen and carbon dioxide were measured using Sensormedics OM-II and LB-2 analysers, respectively. The analysers were calibrated before and after each test with standardisation grade gas mixtures. Oxygen consumption, $\mathrm{CO}_{2}$ production, breathing frequency, and total ventilation (VE) were determined every $15 \mathrm{~s}$. A single mean was calculated for breathing frequency and VE for the entire test period. The total time of the maximum test was determined. For the endurance test, the subject walked on the treadmill at a 0 percent grade and a speed of approximately $3.4 \mathrm{mph}$ for the first $2 \mathrm{~min}$. The elevation was then raised to $5 \%$ and the speed adjusted to $4 \mathrm{mph}$ for women and $5 \mathrm{mph}$ for men for a period of $3 \mathrm{~min}$. The speed of the treadmill was then increased by $0.5 \mathrm{mph}$ every 5 min until the subjects reached $80 \%$ of their maximum heart rate determined by the previous $\dot{\mathrm{V}}_{2}$ max treadmill test. The subject was asked to continue the endurance run until volitional fatigue. Breathing frequency and total time of the endurance run were determined. All subjects underwent continuous ECG monitoring and blood pressure was measured intermittently throughout the course of testing.

During the first month of the study, the men were tested for $\dot{V}_{2}$ max and performed the endurance run $48 \mathrm{~h}$ later. Both tests were repeated $14 \mathrm{~d}$ later. During a control menstrual cycle, the women followed the same testing sequence in random order during the midfollicular and mid-luteal phase, with the first test being performed in either the follicular or the luteal phase and the second test performed in the opposite phase of the cycle. To test the effect of learning, exercise tests were done in random order in either phase of the cycle.

During the second month of study, female subjects were randomly assigned to receive either placebo $(n=3)$ or an oral contraceptive containing $1 \mathrm{mg}$ norethindrone and $35 \mu \mathrm{g}$ of ethinyl oestradiol $(n=7)$ for $21 \mathrm{~d}$ beginning on day 5 of the cycle. Ultrasound and exercise testing, as described earlier, were carried out on the cycle days correlating with the midfollicular and mid-luteal phases, as had been determined during the previous month. The subjects and investigators were blinded as to who was receiving oral contraceptives. Therefore all subjects were advised to use alternative forms of contraception during the period of the study. The study was approved by the West Virginia University Institutional Review Board for the Protection of Human Subjects.

\section{STATISTICS}

Analysis of variance (ANOVA) was used to determine differences in total test time, breathing frequency, and maximum $\mathrm{Vo}_{2}$ across tests for men and women. The per cent change of each variable between the first and second maximum test and the first and second endurance test was calculated for all subjects. An independent $t$ test was done on the percent change to determine if there were differences between men and women. The non-parametric test of group means (Mann-Whitney test) was used to determine differences in endurance test variables between the follicular and luteal phase of the control cycle and pill phase 1 and phase 2 of the experimental cycle. Results are expressed as mean (SD) throughout the text. A probability level (P) of 0.05 was selected as the criterion for statistical significance.

\section{Results}

During the control cycle, ultrasound in the 10 female subjects showed development and 
rupture at the time of expected ovulation. During the second cycle, the three subjects who received placebo were found to have follicle development and rupture. One of the seven subjects who received oral contraceptives developed a $10 \mathrm{~mm}$ follicle which then ceased to grow. The remaining six subjects receiving contraceptives had no follicle development.

Figure 1 represents data from the maximum stress test for the men and the first cycle of the women. There were no differences in total test time, $\mathrm{V}_{\mathrm{O}_{2}} \max$, or breathing frequency between tests 1 and 2 in the women or the men: women: total test time $11.6(\mathrm{SD} \mathrm{2.3)} \mathrm{v} 11.9(2.2) \mathrm{min}$; $\grave{\mathrm{V}}_{2} \max 40.2(8.9) v 39.3(10.9) \mathrm{ml} \cdot \mathrm{kg}^{-1} \cdot \mathrm{min}^{-1}$; breathing frequency $27 \cdot 4(4 \cdot 2) v 27 \cdot 3(4 \cdot 6)$ breaths $\min ^{-1}$; men: total test time $11.9(2 \cdot 2) v$ $12.3(2.6) \mathrm{min} ; \mathrm{Vo}_{2} \max 49.3(9.4)$ v 51.5 $(11 \cdot 5) \mathrm{ml} \cdot \mathrm{kg}^{-1} \cdot \mathrm{min}^{-1}$; breathing frequency $27 \cdot 4$ $(5 \cdot 1)$ v $27 \cdot 0(5 \cdot 0)$ breaths $\cdot \mathrm{min}^{-1}$, respectively. As expected, $\dot{\mathrm{VO}}_{2}$ max was higher in the men then in the women. The first two tests were done without regard to phase of the menstrual cycle and showed that repeating the test did not produce a learning effect. There were no differences in percent change for total test time, $\dot{\mathrm{VO}}_{2} \mathrm{max}$, or breathing frequency between men and women.

Figure 2 represents the results of the endurance run for the men and the control cycle of the women. There was no difference between tests 1 and 2 for total test time, $\hat{\mathrm{Vo}}_{2} \max$, or breathing frequency for the women or the men: women: total test time $17 \cdot 4(11.9)$ v $15 \cdot 2$ $(10 \cdot 8)$ min; $\mathrm{Vo}_{2} \max 35 \cdot 3(8 \cdot 4)$ v 35.1 (7.6) $\mathrm{ml} \cdot \mathrm{kg}^{-1} \cdot \mathrm{min}^{-1}$; breathing frequency $32 \cdot 7(4 \cdot 5) \mathrm{v}$ $34.3(5 \cdot 2)$ breaths $\mathrm{min}^{-1}$; men: total test time $27.8(19.3)$ v $30.5(22.4) \mathrm{min} ; \dot{\mathrm{Vo}}_{2} \max 44.7$ (6.3) $v 47 \cdot 0(7 \cdot 5) \mathrm{ml} \cdot \mathrm{kg}^{-1} \cdot \mathrm{min}^{-1}$; breathing frequency $34 \cdot 0(7 \cdot 0) v 34 \cdot 4(6 \cdot 6)$ breaths $\mathrm{min}^{-1}$, respectively. There was also no difference in the percent change in total test time, $\mathrm{VO}_{2} \max$, or breathing frequency between men and women.

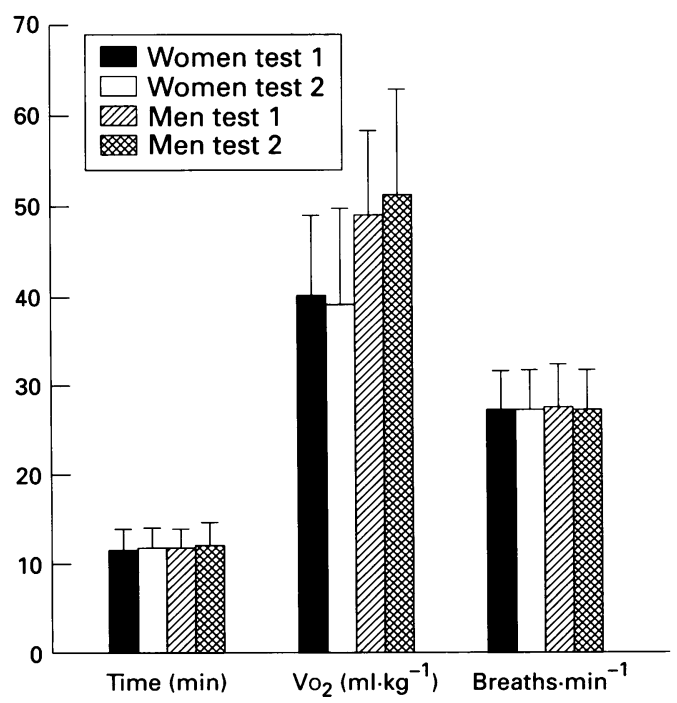

Fig 1 Figure 1 Total time (min), Total time ( $\mathrm{min}$ ), $\mathrm{VO}_{2} \max \left(\mathrm{ml} \cdot \mathrm{kg}^{-1}\right)$, and breaths $\cdot \mathrm{min}^{-1}$ from the endurance run for the control and pill cycle in the women. Error bars $=S D$.

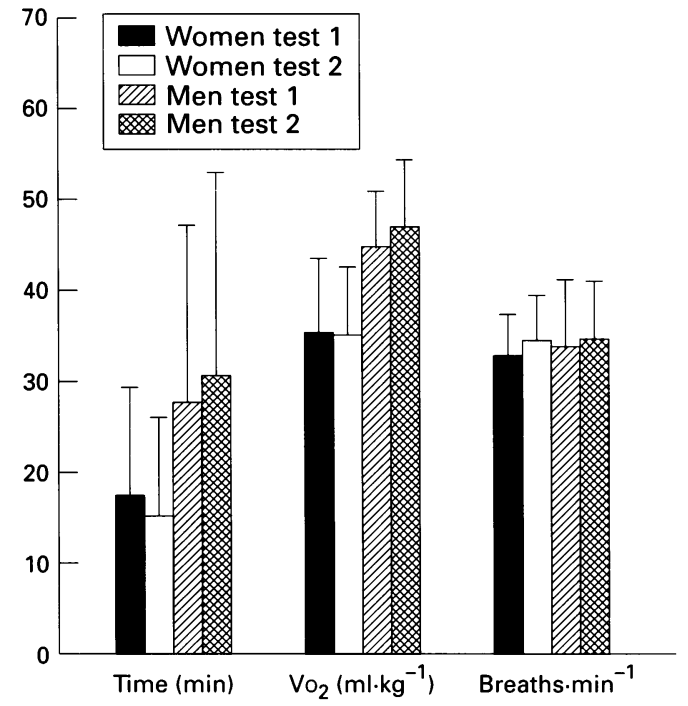

Fig 2 Total time (min), $\mathrm{VO}_{2} \max \left(\mathrm{ml} \cdot \mathrm{kg}^{-1}\right)$, and breaths $\cdot \mathrm{min}^{-1}$ from the endurance run for men and the control cycle for the women. Error bars $=S D$.

Figure 3 represents the results from the maximum stress test for the control and pill cycle in the women. It had previously been shown that the order of tests was not a factor in determining results, therefore, the control cycle was divided into the follicular and luteal phase. The pill cycle was also divided into phases 1 and 2 . There was no difference between the follicular and luteal phase of the menstrual cycle for total test time, $\dot{\mathrm{V}}_{2} \max$, or breathing frequency: total test time $11 \cdot 8(2 \cdot 3)$ $v 12.6(2.3) \mathrm{min} ; \mathrm{V}_{\mathrm{O}_{2}} \max 41.6(12 \cdot 1)$ v 39.7 $(11 \cdot 4) \mathrm{ml} \cdot \mathrm{kg}^{-1} \cdot \mathrm{min}^{-1}$; breathing frequency $26 \cdot 8$ (3.5) $v 27 \cdot 3(9 \cdot 9)$ breaths $\cdot \mathrm{min}^{-1}$, respectively. There was also no difference between phases 1 and 2 during the administration of exogenous progestin: total test time $12.0(2.5) v 12.8$ $(2 \cdot 4) \mathrm{min} ; \mathrm{VO}_{2} \max 37 \cdot 3(7 \cdot 4)$ v $41.0(12 \cdot 4)$ $\mathrm{ml} \cdot \mathrm{kg}^{-1} \cdot \mathrm{min}^{-1}$; breathing frequency $27 \cdot 8(4 \cdot 2) v$ $27 \cdot 7(3 \cdot 4)$ breaths $\cdot \mathrm{min}^{-1}$, respectively. When the results were compared from the follicular and luteal phases of the control cycle to pill

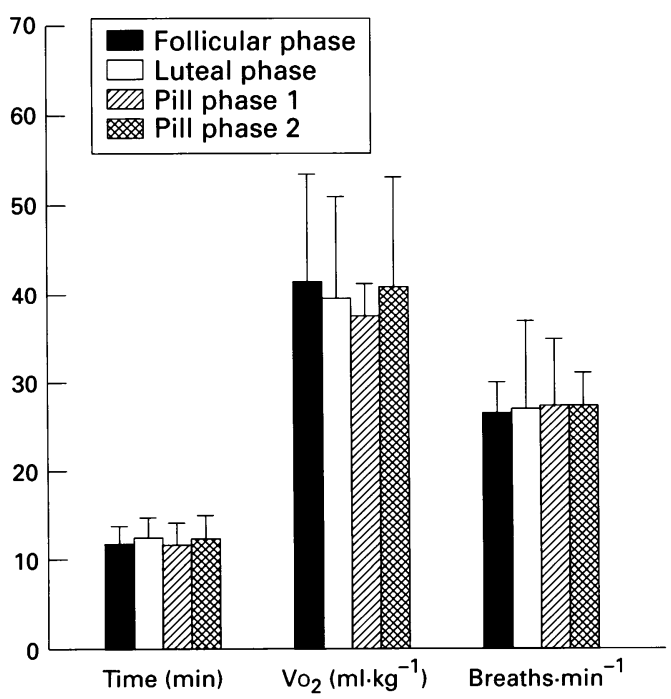

Fig 3 Total time (min), $\mathrm{VO}_{2} \max \left(\mathrm{ml} \cdot \mathrm{kg}^{-1}\right)$, and breaths $\cdot \mathrm{min}^{-1}$ from the maximum stress test for the control and the pill cycle in the women. Error bars $=S D$. 


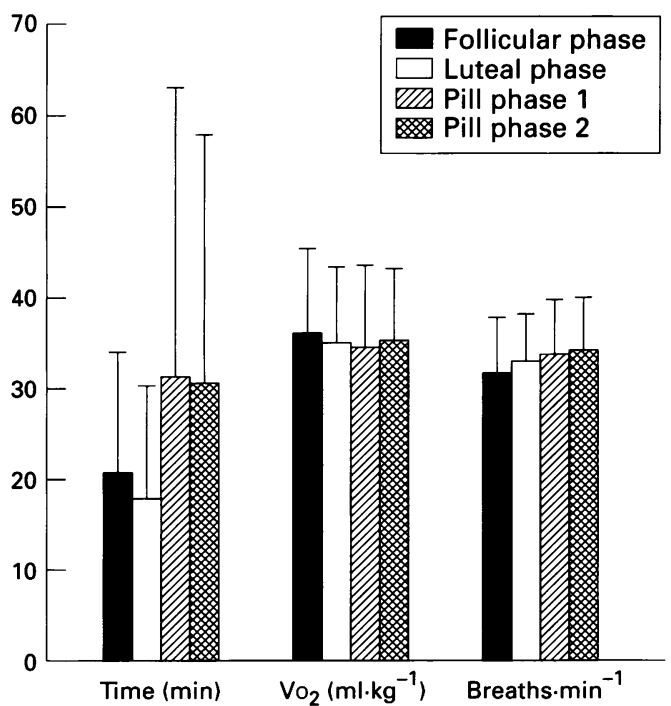

Fig 4 Total time (min), $\mathrm{VO}_{2} \max \left(\mathrm{ml} \cdot \mathrm{kg}^{-1}\right)$, and breaths $\cdot \mathrm{min}^{-1}$ from the endurance run for the control and pill cycle in the women. Error bars $=S D$.

phases 1 and 2 of the pill cycle, no differences were observed for total test time, $\dot{\mathrm{VO}}_{2} \mathrm{max}$, or breathing frequency.

Figure 4 shows the results from the endurance run for the control and pill cycle in the women. The endurance run was used to approximate athletic performance more closely. There was no significant difference between the follicular and luteal phase of the menstrual cycle for total test time, $\mathrm{VO}_{2}$ max, or breathing frequency: total test time $20.8(13.1) v 18.0$ (12.5) min; $\mathrm{VO}_{2} \max 36.2(9.3)$ v $35.2(8.3)$ $\mathrm{ml} \cdot \mathrm{kg}^{-1} \cdot \mathrm{min}^{-1}$; breathing frequency $32 \cdot 0(6 \cdot 0) v$ $33 \cdot 2(5 \cdot 1)$ breaths $\cdot \mathrm{min}^{-1}$, respectively. There was also no difference in each of these variables between phase 1 and 2 of the pill cycle: total test time $31.3(32.0)$ v $30.6(27.5)$ min; $\dot{\mathrm{V}} \mathrm{O}_{2} \max 34.5(9 \cdot 3)$ v $35 \cdot 4(7 \cdot 8) \mathrm{ml} \cdot \mathrm{kg}^{-1} \cdot \mathrm{min}^{-1}$; breathing frequency $34.0(5.9) v 34.8(5.3)$ breaths $\cdot \mathrm{min}^{-1}$, respectively. There was no difference in total test time, $\dot{\mathrm{V}}_{2} \max$, or breathing frequency when the data were compared between the control and pill cycle.

\section{Discussion}

Our results show that the phase of the menstrual cycle or the use of an oral contraceptive containing a synthetic progestin did not alter maximum or endurance test performance. Similar results have been reported by De Souza et $a l,{ }^{9}$ who observed no differences in oxygen uptake, minute ventilation, heart rate, or respiratory exchange ratio between the follicular and luteal phase for both maximum and submaximal exercise. These investigators reported that time to fatigue during maximum exercise was also not affected by menstrual phase. Oral contraceptives are the second most popular form of contraception. Thus many athletes may already be using the pill or are considering its use. A second and perhaps more important consideration is that highly trained athletes often present with disorders of ovulation. If amenorrhea and hypo-oestrogenic states occur, the associated diminution in bone mineral content may lead to acute injuries as well as long term adverse effects upon their health. It has been recommended that oestrogen replacement be offered to such individuals in order to prevent further bone loss and perhaps partially restore that which has already been lost. The inclusion of a progestational agent is common to prevent adverse effects of unopposed oestrogen treatment on the uterus. The effect of this medication on athletic performance has received limited attention.

The observation that natural progesterone was much more effective than the synthetic progestins anhyrohydroxy progesterone, norethinyl testosterone, and 1-2 dehydroprogesterone in stimulating ventilation in patients with pulmonary disease led to the suggestion that the side chain substitution in some way diminished the effect of synthetic progestins upon respiration. ${ }^{2}$ However, Skatrud et al later showed that the synthetic progestin medroxyprogesterone acetate (MPA) also stimulated ventilation. $^{1}$ The administration of MPA did not cause a deterioration in exercise performance, although some subjects did complain of increased exertional dyspnoea. ${ }^{3}{ }^{10}$ Oral contraceptives containing $1 \mathrm{mg}$ norethindrone or $1 \mathrm{mg}$ ethynodiol were also found to stimulate respiration but again did not appear to compromise exercise performance. ${ }^{6}$ In contrast, Notelovitz et al described a $7 \%$ deterioration in exercise performance in women using an oral contraceptive containing $0.4 \mathrm{mg}$ norethindrone $\mathrm{f}^{7}$; and Daggett and coworkers described an $11 \%$ deterioration in performance with an oral contraceptive containing $0.25 \mathrm{mg}$ levonorgestral. ${ }^{5}$

Initial observations on our data suggest a trend toward deterioration in maximum oxygen uptake and endurance during the luteal phase, and an apparent improvement in endurance while using the oral contraceptive. Chronic oral contraceptive use has been shown to enhance growth hormone responses, lower blood glucose levels, and diminish carbohydrate oxidation during prolonged treadmill exercise. ${ }^{11}$ This could theoretically enhance prolonged exercise by facilitating an increased reliance on fats while having a carbohydrate sparing effect. Statistical analysis of our data does not, however, support the view that cycle phase or a low dose oral contraceptive has an effect of upon $\mathrm{VO}_{2}$ max or endurance. The large variation in the level of conditioning and the resulting large standard deviation in the measured variables may be the reason for the lack of significance. Analysis of data on individual subjects, however, also failed to show an effect of cycle phase or the use of oral contraceptives upon $\mathrm{VO}_{2}$ max or endurance.

The suggestion that the use of oral contraceptives will diminish athletic performance has led many trainers, coaches, and athletes to avoid their use, thus depriving the female athlete of the many benefits that the pill has to offer. Our findings suggest that a low dose oral contraceptive does not adversely affect performance during a maximal treadmill test. Perhaps more importantly, the lack of effect of the pill during an endurance run could have far reaching effects upon recommendations for health care in women. 
This research was supported by the WVU Medical Corporation and NIH biomedical research grant No 2 S07 RR05433-26.

1 Skatrud JB, Dempsey JA, Kaiser DG. Ventilatory response to medroxyprogesterone acetate in normal subjects: time course and mechanism. $f$ Appl Physiol 1978;44:939-44.

course and mechanism. F Appl Physiol 1978;44:939-44.
2 Tyler JM. The effect of progesterone on the respiration of patients with emphysema and hypercapnia. $\mathcal{f}$ Clin Invest patients with emp

3 Robertson HT, Schoene RB, Pierson DJ. Augmentation of exercise ventilation by medroxyprogesterone acetate. Clin

4 Martin BJ, Hsium-Ing C, Kolka MA. Anaerobic metabolism of the respiratory muscles during exercise. Med $S c i$ Sports Exerc 1984;16:82-6.

5 Daggett A, Davis B, Boobis L. Physiological and biochemical responses to exercise following oral contraceptive use [abstr]. Med Sci Sports Exerc 1983;15:174.
6 Montest A, Lally D, Hale RW. The effects of oral contraceptives on respiration. Fertil Steril 1983;39:515-9.

7 Notelovitz M, Cauner C, McKenzie L, Suggs Y, Fields C, Kitchens C. The effect of low-dose oral contraceptives on cardiorespiratory function, coagulation, and lipids in exercising young women; a preliminary report. $A m \mathcal{F}$ Obstet Gynecol 1987;156:591-8.

8 Balke B, Ware RW. An experimental study of physical fitness of Air Force personnel. US Armed Forces Med F 1959;10: of Air For

9 De Souza MJ, Maguire MS, Rubin KR, Maresh CM. Effects of menstrual phase and amenorrhea on exercise performance in runners. Med Sci Sports Exerc 1990;22: $575-80$

10 Bonekat HW, Dombovy ML, Staats BA. Progesteroneinduced changes in exercise performance and ventilatory responses. Med Sci Sports Exerc 1987;19:1 18-23.

11 Bemben DD, Boileau RA, Bahr JM, Nelson RA, Misner JE. Effects of oral contraceptives on hormonal and metabolic responses during exercise. Med Sci Sports Exerc 1992;24: 434-41.

\section{BASM Merchandise 1995}

Ladies scarves White with blue border and BASM logo - 27-inch square

$£ 5+£ 1 \mathrm{p} \& \mathrm{p}$ Navy blue with fringe and BASM logo $54 \times 9$ inches (oblong)

Ties

Single motif

$£ 6+£ 1 \mathrm{p} \& \mathrm{p}$

Multi motif

$£ 6+£ 1 \mathrm{p} \& \mathrm{p}$

Blazer badge

Wire -4 inches high

$£ 5+£ 1 \mathrm{p} \& \mathrm{p}$

Wire -3 inches high

$£ 5+£ 1 \mathrm{p} \& \mathrm{p}$

\section{New stock to order}

Sweaters

Lambswool fine knit, V-neck or round neck with small motif.

$£ 32+£ 1 \mathrm{p} \& \mathrm{p}$

Machine washable. State colour and chest size required.

Slipovers

Lambswool fine knit, V-neck, with small motif. Machine

$£ 30+£ 1 \mathrm{p} \& \mathrm{p}$ washable. State colour and chest size required.

Sweatshirts

With small motif.

State colour and chest size required.

$£ 20+£ 1 \mathrm{p} \& \mathrm{p}$

Polo shirts

With small motif.

$£ 18+£ 1 \mathrm{p} \& \mathrm{p}$

State colour and chest size required.

Send orders to John H Clegg JP LDS RCS Eng, Hon Secretary, Birch Lea, 67 Springfield Lane, Eccleston, St Helens, Merseyside WA10 5HB, UK. (Tel: 01744 28198) 